\title{
ARENDT E MARX, TRABALHO, FABRICAÇÃO
}

\author{
Arendt and Marx, labor, work
}

Samir Haddad 1

\section{RESUMO}

A distinção que Arendt estabelece entre trabalho e fabricação tem o mérito de esclarecer, conceitualmente, significativas diferenças entre as atividades humanas que constituem o que ela chamou de vita activa. Essas distinções adquirem pleno significado em contraste com o pensamento de Marx, nasceram da tentativa de fazer do homem alguma coisa a mais que o reprodutor de si mesmo e produtor de objetos. Procuramos nesse texto refletir sobre alguns temas do diálogo implícito com Marx que percorre a obra de Arendt.

Palavras-chave: Arendt, Marx, Trabalho, fabricação, ação

\section{ABSTRACT}

Arendt's distinction between labor and work has the merit of clarifying, conceptually, significant differences between human activities that constitute what she called vita activa. These distinctions acquire full significance in contrast to Marx's thought, they are born from the attempt to make man something more than the reproducer of himself and the producer of objects. We try in this text to reflect on some of the themes of the implicit dialog with Marx that runs through Arendt's work.

Keywords: Arendt, Marx, labor, work, action

A distinção entre labor(trabalho) e work (fabricação-obra) realizada por Arendt ${ }^{2}$ tem o mérito de esclarecer, conceitualmente, significativas diferenças entre as atividades humanas que constituem o que ela chamou de vita activa. Mas, também, tem por objetivo responder e contrapor-se à perspectiva Marx na qual o labor ${ }^{3}$ (trabalho-Arbeit) é compreendido como a atividade mais digna do homem. Na visão de Marx, o homem é produto de suas relações com a natureza (labor-trabalhoArbeit). A esta formulação da essência do homem, Arendt contrapõe a ação e o discurso, isto é, a política, como a atividade fundamental, estabelecendo uma hierarquia entre as diversas atividades da vita activa. O ponto mais baixo é o trabalho, cujo produto é inteiramente consumido em seu ciclo biológico; seguido da fabricação e da construção da durabilidade do mundo, mas coroado pela ação, que é a atividade dos homens por excelência, pois é exercida sem nenhuma mediação; os homens se

\footnotetext{
${ }^{1}$ Professor da Faculdade de Filosofia da Universidade Federal do Estado do Rio de Janeiro - UNIRIO. Email:samirfilo@gmail.com

2 Para manter a integridade das palavras iremos usar no original algumas expressões chaves quando isso for necessário. Para evitar ambiguidade esclarecemos que a palavra labor quando utilizada neste texto se refere ao termo em inglês empregado por Arendt no original. $O$ aviso é necessário na medida em que até a $10^{a}$ edição em português da obra $A$ condição bumana, a tradução de labor tem a mesma grafia em português e inglês.

3 Arendt usa tanto em $A$ condição bumana quanto em $A$ tradição e a Época Moderna a expressão labor para se referir ao tratamento que Marx dá a questão.

ARENDT, Hannah. A condição bumana. Tradução Roberto Raposo, revisão técnica: Adriano Correia - $11^{\mathrm{a}}$ ed.. Rio de Janeiro. Forense Universitária, 2010.

ARENDT, Hannah. A tradição e a época Moderna. In: Entre o passado e o futuro. São Paulo: Editora Perspectiva, 1992.
} 
encontram na ação e no discurso enquanto homens, e a vida sem a ação não poderia mais ser considerada humana. ${ }^{4}$

A crítica de Arendt dirigida a Marx, relativa ao trabalho, se desenvolve em torno de alguns eixos principais: Marx não distinguiria labor e work (trabalho e fabricação); pensava a atividade da fabricação da perspectiva do trabalho; glorificou o trabalho(labor) como a atividade fundamental do homem; transformou o homem em animal laborans, opondo-se ao pensamento da tradição. Essas críticas são resumidas por Arendt em uma citação de Engels ${ }^{5}$ - Labor created man - que para Arendt significaria que:

em primeiro lugar, que o trabalho, e não Deus, criou o homem; em segundo lugar, que o homem, na medida em que é humano, cria a si mesmo, que sua humanidade é resultado de sua própria atividade; significa, em terceiro lugar, que aquilo que distingue o homem do animal, sua diferentia specifica, não é a razão, mas sim o trabalho, e que ele não é um animal rationale, mas sim um animal laborans; em quarto lugar que não é a razão, e até então o atributo máximo do homem, mas sim o trabalho, a atividade humana tradicionalmente mais desprezada, aquilo que contém a humanidade do homem. Marx desafia assim o Deus tradicional, o juízo tradicional sobre o trabalho e a tradicional glorificação da razão. ${ }^{6}$

Para Arendt, "a criação do homem através do trabalbo humano foi uma das mais

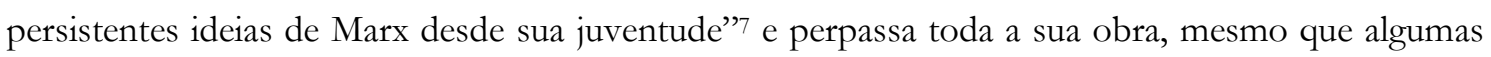
vezes de forma implícita. Entretanto, o que Marx chama genericamente de "Arbeit-trabalho" não tem para Arendt as características da fabricação, mas é a sua própria definição de labor. Ao definir o trabalho como "o metabolismo do homem com a natureza em cujo processo o material da natureza é adaptado, por uma mudança de forma às necessidades do homem", 8 Marx teria deixado claro que se referia ao processo fisiológico. A "humanidade" do homem é definida por sua relação com a natureza, o homem aparece historicamente como resultado do "trabalho" que impõe à natureza, criando-se a si mesmo e distinguindo-se dos outros seres.

Pode-se distinguir os homens dos animais pela consciência, pela religião ou por tudo que se queira. Mas eles próprios começam a se diferenciar dos animais tão logo começam a produzir seus meios de vida.

Tal como os indivíduos manifestam sua vida, assim são eles. O que eles são coincide, portanto, com sua produção, tanto com o que produzem, como o modo como produzem. O que os indivíduos são, portanto, depende das condições materiais de sua produção. ${ }^{9}$

\footnotetext{
${ }^{4}$ uma vida sem discurso e sem ação... é literalmente morta para o mundo; deixa de ser uma vida humana, uma vez que já não é vivida entre os homens. A condição bumana. Op. cit p. 221.

5 ENGELS, F. Sobre o papel do trabalho na transformação do macaco em homem. In: MARX, K., ENGELS. Obras Escolbidas. São Paulo: Editora Alfa-Omega. s/d. v. 2. p. 269.

${ }^{6}$ ARENDT, Hannah. A Tradição e a Época Moderna. In: Entre o passado e o futuro. Op. cit. p. 48.

7 A condição humana. Op. cit. p.106, nota 14 - no original: The creation of man through human labor. ARENDT, Hannah. The Human Condition. Chicago. University of Chicago Press, 1998. p.86.

8 A condição humana. Op. cit. p. 122.

9 MARX, K., ENGELS. A ideologia alemã. Trad. José Carlos Bruni, Marco A. Nogueira. São Paulo: Hucitec, 1993. p. 27 ss.
} 
$\mathrm{Na}$ análise de Arendt, a indistinção entre trabalbo e fabricação, em Marx, foi o resultado do momento histórico em que ele vivia; a revolução industrial na era moderna revelou o enorme potencial da produtividade do trabalho (labor) humano. A substituição do artesão pelo operário destruiu as antigas ligações que o trabalhador guardava com o produto de seu trabalho e, assim, na época moderna os produtos da fabricaşão se transformaram em produtos do trabalho. O destino das coisas produzidas pelo trabalho na sociedade moderna é ser consumido imediatamente, o que acaba com as diferenças entre os produtos da fabricação e os frutos do trabalbo, as quais são as bases da distinção de Arendt: '... realmente, a maior parte da obra no mundo moderno é realizado sob forma de trabalho..."10

Para Arendt, Marx pôde conceber uma sociedade de operários porque baseou-se no trabalho, cuja inerente fertilidade tem possibilidade de produzir a abundância, "que é o ideal do animal laborans". ${ }^{11}$ Trabalbo e fabricação são reduzidos à "força de trabalho" (labor power), que como tal se assemelha e contém fundamentalmente a ideia de produtividade, que é inerente ao trabalbo:

Essa produtividade não reside em qualquer um dos produtos do trabalho, mas na 'força' humana, cujo vigor não se esgota depois que ela produz os meios de sua subsistência e sobrevivência, mas é capaz de produzir um 'excedente', isto é, mais que o necessário à sua reprodução. ${ }^{12}$

De fato, Marx, em $O$ Capital 13 não diferencia entre trabalho qualificado e trabalho não qualificado. Ele usa a expressão "trabalho simples" e "trabalho complexo", os quais não se diferenciam pela natureza da atividade ou do produto, mas a diferença é de grau, podendo um ser reduzido ao outro.

O trabalho é, para Marx, sua atividade vital mais significativa e o homem é essencialmente um animal laborans. Entretanto, pergunta Arendt, o que acontecerá quando, depois da revolução, o trabalho for abolido no reino da liberdade, que é o projeto e ideal de Marx? Por toda a sua obra, diz ela, Marx interpreta o homem a partir da atividade do trabalho, isto é, como um animal laborans, e depois concebe uma sociedade na qual sua atividade fundamental não será mais necessária. O que Arendt propõe é considerar o homem não apenas como um animal que trabalha, mas um ser que tem a capacidade de agir em conjunto.

O ponto de partida de Arendt e o de Marx são distintos. Arendt, ao procurar estabelecer as diferenças entre as atividades humanas da vita activa, parte das características do produto resultante

\footnotetext{
10 A condição humana. Op. cit. p. 175.

11 A condição humana. Op. cit. p. 156.

12 A condição bumana. Op. cit. p. 108.

13 MARX, K. O Capital. Trad. Regis Barbosa, Flávio R. Kothe. Apresentação de Jacob Gorender. São Paulo: Nova Cultural, 1996. p. 173 ss. "Trabalho mais complexo vale apenas como trabalho simples potenciado ou, antes, multiplicado, de maneira que um pequeno quantum de trabalho complexo é igual a um grande quantum de trabalho simples."
} 
dessas atividades ${ }^{14} \mathrm{e}$ da localização das atividades, enquanto Marx dirige seu olhar para o ente que é responsável pelas atividades, tanto na forma do trabalho quanto na forma da fabricação. Temos como hipótese que a distinção que Arendt estabelece entre trabalho e fabricação só adquire pleno significado em contraste com o pensamento de Marx, e que esses conceitos nasceram da tentativa de fazer do homem alguma coisa a mais que o reprodutor de si mesmo e produtor de objetos..$^{15}$

É um elemento indispensável do orgulho humano acreditar que quem alguém é transcende em grandeza e importância, qualquer coisa que esse alguém possa fazer ou produzir. ${ }^{16}$

É este pressuposto que fundamenta as distinções no âmbito da vita activa, o qual permite a Arendt contrapor à ideia de que "o trabalho é criador do homem" a concepção que a ação e o discurso são as atividades que podem distinguir os homens. Sua preocupação principal não estava, simplesmente, em separar e caracterizar trabalho e fabricação, mas em destacar a ação, fundamentada na condição humana da pluralidade, que: "a medida em que se empenha em fundar e preservar corpos políticos, cria a condição para a lembrança [remembrance], ou seja, para a história"17.

O marxismo tem um nome clássico para a posição de Marx - materialismo histórico e a “determinação em última instância do econômico, já que toda e qualquer questão histórica que se coloque depende das implicações dialéticas desta determinação". ${ }^{18}$ Para Marx, as "relações de produção" são as relações fundamentais que devem ser investigadas. Nas palavras de Isaiah Berlin, "Marx nunca publicou uma exposição formal do materialismo histórico. Ela se acha em forma fragmentária em toda a sua obra inicial escrita entre 1843 e 1848”. ${ }^{19}$ Entretanto, é forçoso admitir que nesta 'nova teoria' "a história da humanidade é um processo único, não repetitivo, que obedece a leis que podem ser descobertas". ${ }^{20}$ Quanto ao conceito de história, materialismo e a importância do econômico as posições de Marx e Arendt são irreconciliáveis. Para Arendt, a

${ }^{14} \mathrm{O}$ que nos surpreende visto que Arendt tem um olhar muito crítico em relação ao utilitarismo e suas categorias de meios e fins.

${ }^{15} \mathrm{Em} A$ vida do espirito, vinte anos após a publicação de $A$ condição bumana, Arendt, tentando recuperar o tema da vita activa e da vita contemplativa, nos dá uma explicação sobre o seu interesse na vita activa. "O que me interessava no estudo sobre a Vita activa era que a noção de completa inquietude da Vita contemplativa era tão avassaladora que, em comparação com ela, todas as diferenças entre as diversas atividades da Vita activa desapareceriam." (ARENDT, Hannah. A vida do espírito. O pensar, o querer, o julgar. Trad. Antônio Abranches, César A. R. de Almeida, Helena Martins. Rio de Janeiro: Relume-Dumará,1993. p. 8.).Parece-nos, entretanto, que essa justificativa procura explicar os conceitos que elabora em $A$ condição bumana a partir daqueles que seriam tratados em $A$ vida do espirito, o que não corresponderia exatamente à ideia inicial. No prefácio de $A$ condição bumana, Arendt nos diz que: "O que proponho nas páginas que se seguem é uma reconsideração da condição humana à luz de nossas mais novas experiências e nossos temores mais recentes." Que neste caso se referiam à experiência totalitária, a glorificação do trabalho na era moderna e o perigo de uma sociedade de trabalhadores sem trabalho, incapazes de restaurar as outras capacidades humanas. Tratava-se de "pensar o que estamos fazendo".(A condição bumana. Op. cit. p. 5/6.)

16 A condição bumana. Op. cit. p. 263.

17 A condição bumana. Op. cit. p.10

${ }^{18}$ ESCOBAR, C.H. Ciência da história e ideologia. Rio de Janeiro: Edições Graal, 1979. p. 51.

19 BERLIN, Isaiah. Materialismo bistórico. In: BOTTOMORE, Tom. Org. Karl Marx. Trad. Nathanael C. Caixeiro. Rio de Janeiro: Zahar Editores, 1981. p.59.

${ }^{20}$ Ibid. p. 60. 
história não possui nem a racionalidade, nem a determinação que Marx e Hegel supuseram e a realidade econômica passa para segundo plano. Para ela, o homem, em certa medida, é não-natural; naturais são suas condições, sobre as quais e a partir das quais pode tornar-se homem, e a distinção fundamental não é o trabalho nem a fabricação, mas a ação e o discurso que permitem ao homem revelarem-se reciprocamente como seres singulares.

A experiência dos campos de concentração demonstra realmente que os seres humanos podem transformar-se em espécimes do animal humano, e que a 'natureza' do homem só é 'humana' na medida em que dá ao homem a possibilidade de tornar-se algo eminentemente não-natural, isto é, um homem. ${ }^{21}$

Poderíamos dizer, contudo, que o conceito de natureza humana de Marx era menos fragmentado do que o conceito de "condição humana" de Hannah Arendt. Não havia, para ele, distinção possível entre o produto das mãos (fabricação), o produto do corpo (trabalho), assim como não havia a possibilidade de conceber separadamente uma realidade interna (pensamento / atividades da mente) separada da realidade externa (mundo da práxis / vita activa). O homem é, para Marx, uma espécie de animal que é capaz de crescimento constante através de sua interação com a natureza, da qual nunca se afasta completamente. A história humana:

É um processo natural em que o homem não se separa da natureza e se desenvolve como ser da natureza. Mas é o processo de um ser que luta contra a natureza e conquista, através deste embate incessante..., graus cada vez mais elevados de poderio e de consciência. ${ }^{22}$

A história seria o relato da conquista pelo homem, também, de seu próprio corpo. A frase de Engels, que Arendt escolhe como paradigma da concepção de Marx - O trabalho (labor) criou o homem - é dita dentro deste contexto.

"O trabalho é o criador do homem" aparece em um texto no qual Engels, ${ }^{23}$ procura mostrar como o desenvolvimento do macaco em homem se deu, material e historicamente, pelo uso de seu corpo, principalmente suas mãos, na fabricação de instrumentos - isto é, trabalho - e como isto produziu historicamente o homem. O contexto é inteiramente materialista. O trabalho como criador do homem a que Engels se refere é uma teoria biológica-histórica do desenvolvimento do macaco em homem. A mão não seria um órgão do trabalho, mas o produto do trabalho, foi a necessidade de produzir sua própria subsistência que transformou patas em mãos. O trecho completo de onde Arendt retira a afirmação é:

O trabalho é a fonte de toda riqueza, afirmam os economistas. Assim é, com efeito, ao lado da natureza, encarregada de fornecer os materiais que ele converte em riqueza. O trabalho, porém, é muitíssimo mais do que isso. É a condição básica e fundamental de toda a vida

\footnotetext{
21 ARENDT, Hannah. Origens do totalitarismo. Trad. Roberto Raposo. 3v: Anti-semitismo, imperialismo, totalitarismo. São Paulo: Companhia das Letras, 1989. p. 506.

22 LEFEBVRE, Henri. O marxismo. Trad. J. Guinsburg. São Paulo: Difusão Européia do Livro, 1974. p. 52.

${ }^{23}$ ENGELS, Friedrich Sobre o papel do trabalho na transformação do macaco em homem. In: MARX, K., ENGELS. Obras Escolhidas. São Paulo: Editora Alfa-Omega. s/d. v.2.
} 
humana. E em tal grau que, até certo ponto, podemos afirmar que o trabalho criou o próprio homem. ${ }^{24}$

Vemos, pois, que a mão não é apenas o órgão do trabalho; é também produto dele. Unicamente pelo trabalho, pela adaptação a novas e novas funções, pela transmissão hereditária do aperfeiçoamento especial assim adquirido pelos músculos e ligamentos e, num período mais amplo, também pelos ossos; unicamente pela aplicação sempre renovada dessas habilidades transmitidas a funções novas e cada vez mais complexas foi que a mão do homem atingiu esse grau de perfeição que pôde dar vida, como por artes de magia, aos quadros de Rafael, às estátuas de Thorwaldsen e à música de Paganini. ${ }^{25}$

O mesmo processo será aplicado ao aparecimento da linguagem e ao desenvolvimento simultâneo da laringe, que será explicado através da necessidade de comunicar ao outro suas necessidades. Engels insiste na comparação entre animais e homens a partir do trabalho e pelo trabalho até chegar ao cérebro humano e ao homem propriamente dito. O trabalho e a linguagem foram os estímulos principais que levaram à transformação gradual do cérebro do macaco em cérebro humano. O trabalho começa pela criação de instrumentos que moldam ao mesmo tempo as mãos humanas. Engels procura descrever a importância do trabalho no desenvolvimento biológico do homem, o que está muito distante das preocupações de Arendt, aqui o trabalho não aparece como uma atividade humana, mas como o responsável pela humanidade do homem. Em certa medida, a citação de Engels, como paradigma da posição de Marx, e a fixação do trabalho como a atividade fundamental do homem, foi interpretada por Arendt fora do contexto. Em seus argumentos ela não se refere ao caráter materialista da formulação de Engels e à constante referência a Darwin, o que revela a distância teórica que separa as formulações de Marx e Arendt.

A indistinção entre o trabalho e a fabricação que Arendt critica em Marx é contestada por Engels em uma nota à quarta edição inglesa de O Capital, na passagem na qual Marx, no primeiro capítulo da obra, afirma a dupla natureza do trabalbo:

Todo trabalho, é por um lado, dispêndio de força de trabalho do homem no sentido fisiológico, e nessa qualidade de trabalho humano igual ou trabalho humano abstrato gera o valor da mercadoria. Todo trabalho é, por outro lado, dispêndio de força de trabalho do homem sob a forma especificamente adequada a um fim, e nessa qualidade de trabalho concreto útil produz valores de uso. ${ }^{26}$

Engels nos diz que este duplo aspecto do trabalho corresponde na língua inglesa a dois conceitos distintos:

A língua inglesa tem a vantagem de possuir duas palavras distintas para esses dois aspectos diferentes do trabalho. O trabalho que gera valores de uso e é qualitativamente determinado

\footnotetext{
${ }^{24}$ Ibid. p. 267.

25 Ibid. p. 270.

${ }^{26}$ MARX, K. O Capital. Op. cit. p. 175.
} 
chama-se de work, em oposição a labour, o trabalbo que cria valor e é medido apenas quantitativamente chama-se labour, em oposição a work..27

Marx havia percebido que o trabalho se dá de duas formas diferentes, conforme o objeto que produz; se produz um objeto que deve perdurar como objeto para uso, é um objeto qualitativamente diferente, enquanto o trabalbo que pode ser medido apenas quantitativamente, o trabalho que produz mercadorias em uma sociedade cujo modo de produção é capitalista chama-se labour28. O nome é apropriado e guarda relações com a distinção entre work (fabricação) e labor (trabalho) que nos fala Arendt, pois é trabalho alienado, trabalho que é feito para ser trocado e consumido, tem durabilidade circunstancial, não foi feito para ser usado, mas trocado, o valor de uso que possui está desvinculado daquele que o produziu. Quem o produziu gastou o seu corpo, apenas isto, não incorporou um "objeto" ao mundo, mas uma "mercadoria". E a mercadoria para Marx não é (na linguagem de Arendt) resultado da fabricação, mas do trabalho. O operário enquanto vende sua força de trabalho, no modo capitalista de produção, não se assemelha ao artífice, mas ao escravo. Mercadoria para Marx não são objetos pura e simplesmente, mas "uma coisa complicada, cheia de sutileza metafísica e manhas teológicas". ${ }^{29}$

Agnes Heller ${ }^{30}$ também havia mostrado que a distinção entre fabricação e trabalho já havia sido feita por Marx, mas sob perspectiva diferente da de Arendt. Para Arendt, o trabalbo e a fabricação seriam atividades distintas, enquanto para Marx seria um duplo aspecto de uma mesma atividade. Mesmo ao separar fabricação e trabalho pelo ponto de vista objetivo do resultado do trabalho, Arendt não poderia deixar de concordar com Marx que tanto o trabalho quanto a fabricação, o que produz valor de uso e o que produz valor de troca, ou mercadoria são ambos "funções do organismo humano e que cada uma dessas funções, qualquer que seja seu conteúdo ou formas, é essencialmente dispêndio de cérebro, nervos, músculos, sentidos etc. humanos". ${ }^{31}$ Devemos reconhecer que apesar de do ponto de vista dos produtos resultantes e da localização das atividades, fabricação e trabalho se distinguirem, ambos são fisiologicamente a mesma coisa.

O trabalho produz não só coisas usáveis e permanentes, com valor de uso, mas produz mercadoria, e a mercadoria, ainda que dure e permaneça no mundo possuindo certa durabilidade, é ainda mercadoria e como tal algo para ser trocado e consumido. Na sociedade industrial ambos os processos tendem a se igualar. A distinção entre o trabalbo que produz valor de uso e o trabalho que produz valor de troca é clara em Marx, e mesmo que Marx não tenha invocado "a valia objetiva "intrínseca" [“instrinsick" objective worth] à própria coisa"32 como resposta ao fato de cada coisa tenha

\footnotetext{
${ }^{27}$ Ibid p. 176. nota 95.

${ }^{28}$ Dessa forma aparece no original em inglês.

${ }^{29}$ Ibid. p. 197.

${ }^{30}$ HELLER, Agnes. Sociología de la vida cotidiana. Prefacio de György Lukacs. Trad. J.F. Yvars, E. Pérez Nadal. Barcelona: Ediciones Península, 1994. p. 119.

31 MARX, K. O Capital. Op. cit. pp. 197-198.

${ }^{32}$ A condição humana. Op. cit. p. 206.
} 
se tornado na sociedade moderna um valor intercambiável, é ainda claro, que o mesmo homem que produz valor de uso é aquele que produz valores de troca, por isso Marx não acentua as diferenças entre os produtos, mas vai direto naquele ser - o homem, na forma do operário, que é responsável por ambos.

De fato, a distinção que faz Arendt, apesar de fundamental como instrumento interpretativo, não resolve ou soluciona a questão que preocupava Marx. A posição de Arendt é que Marx promove o trabalho à mais alta categoria, mas ele não promove o trabalho, e sim aquele que é responsável pelo trabalho e pela fabricação, aquele que produz para seu próprio consumo e o consumo de outros, e além disso é responsável pela produção dos objetos do mundo, seja como escravo, artesão ou proletário. Arendt, concentra sua atenção não no homem como produtor ou construtor do mundo, mas no homem capaz de agir livremente. Marx não "inventou" a modernidade nem a revolução industrial. $O$ que ele percebeu é que a única força ainda ativa, na sociedade moderna, era a força do trabalho. $\mathrm{O}$ artífice, o fabricante de objetos, mestre artesão que sozinho dominava todas as fases do processo de fabricação não mais existia, tragado pela necessidade urgente de se produzir em massa para uma sociedade de massa, alimentado pela técnica e o desejo de lucro. Foi a tentativa de mobilizar essa única força restante que levou Marx a dirigir para aí o seu olhar. Estando todos os homens transformados em homens que laboram, a possibilidade de liberdade e ação política estava negada pela ausência de tempo livre e pelo isolamento do trabalho. A ação política, no início do processo de produção capitalista, estava aberta a uns poucos homens livres e privilegiados que dispunham de seu tempo. A liberdade na sociedade capitalista ainda seria a mesma liberdade que Arendt percebe no mundo grego, isto é, a liberdade da necessidade, o poder dispor de seu tempo, ainda que este tempo livre na modernidade, não seja usado na atividade política, mas no desfrute da privacidade.

Marx já havia comparado os operários fabris ingleses aos escravos, não glorificava o trabalho, mas mostrava que é ele o sustentáculo das demais atividades; quer que a liberdade seja a liberdade de todos, pois segundo ele é esta a essência humana:

A liberdade constitui de tal modo a essência do homem que até mesmo os seus adversários a realizam ao combater a realidade dela... A liberdade, pois, sempre existiu, ora como privilégio particular, ora como direito geral..$^{33}$

Nesse ponto o diálogo entre Marx e Arendt torna-se problemático. Para Arendt não é possível determinar a essência humana, podemos dizer que o homem é um ser condicionado, mas isso nada diz sobre sua essência. Mesmo a política, cujo sentido é a liberdade, não pode ser atribuída à essência do homem - o homem não é zoon politikon, o homem é a-político, porque a política se dá entre os homens, portanto fora deles, no espaço entre eles, não é um atributo interno aos

33 MARX, A liberdade de Imprensa. Apud ALTHUSSER, Louis. A favor de Marx. Trad. Dirceu Lindoso. Rio de Janeiro: Zahar Editores, 1979. p. 197. 
homens, assim como a liberdade é um "estado objetivo da existência humana" e não um "problema de subjetividade, de uma vontade inteiramente indeterminada ou determinada"34, portanto não é a essência humana, mas uma possibilidade aberta que se dá, também, entre os homens.

$\mathrm{Na}$ interpretação de Arendt, Marx teria glorificado o trabalho, e ao mesmo tempo quis acabar com ele na futura sociedade comunista. De fato, ele glorificou os homens que estavam submetidos a esta condição, e sonhou com uma sociedade na qual o trabalho é dividido e a fabricação de objetos de uso, e não mercadorias, seria realizado.

O que Marx advoga é simplesmente tempo livre, o mesmo tempo livre que Arendt, no exemplo grego, exige como fundamental para a atividade verdadeiramente humana da política. A abolição do trabalho, diz Marx, não é o fim da necessidade, mas:

Efetivamente o reino da liberdade apenas começa onde se deixa de trabalhar por necessidade e oportunidade imposta de fora (grifo nosso)... Porém esta atividade (as trocas com a natureza - trabalbo) constituirá sempre o reino da necessidade. É para além dele que começa o desenvolvimento das forças humanas como fim em si, o verdadeiro reino da liberdade que só pode desabrochar fundando-se sobre outro reino, sobre outra base, a da necessidade. A condição essencial para este florescimento é a redução da jornada de trabalho. ${ }^{35}$

Marx não está só valorizando o trabalho, mas pretende racionalizá-lo (a sua necessidade) o mais completamente possível, de tal forma que tempo livre possa ser compartilhado.

Ao comentar o contínuo desenvolvimento tecnológico, ${ }^{36}$ ele afirma que o aprimoramento da técnica e a racionalização do trabalho não tem servido para "aliviar a necessidade", mas para poder roubar ainda mais tempo, que seria tempo livre do operário; "a indústria cria tempo disponível, para, por outro, o transformar em sobretrabalho"; 37 ao usar da técnica para diminuir o tempo de produção e aumentar o tempo livre não busca com isso a satisfação da necessidade, mas o aumento da apropriação do trabalho; a solução proposta por Marx é que "as massas devem se apropriar de seu sobretrabalho". 38

Sem o trabalho não é possível a vida, assim como sem a fabricação e construção de mundo a ação é impossível. Trata-se de valorizar o que está por detrás das condições de liberdade. Ao discutir o trabalho, Marx reafirma a posição de que o homem é liberdade, mas essa liberdade só é possível quando e se as condições fundamentais estão satisfeitas, isto é, está seguro o ciclo biológico e existe um mundo como cenário, onde a ação e o discurso podem “aparecer”. O aparecer depende de certa forma deste cenário criado pelo trabalho e pela fabricação humana. Está claro que o

\footnotetext{
34 A Condição Humana. Op. Cit. p. 87

35 MARX, ENGELS, LENINE. Sobre o humanismo na sociedade comunista. Coletânea de extratos. Lisboa: Seara Nova, 1977. p. 66. Citado de O Capital, Livro 3, Tomo III.

36 MARX, K., ENGELS, LENINE. Op. Cit. Sobre o bumanismo na sociedade comunista.Op. cit. p. 62.

${ }^{37} \mathrm{Id}$.

${ }^{38} \mathrm{Id}$.
} 
homem pode colocar outros para trabalhar para si, e pode também não acrescentar nenhum objeto ao mundo, mas não pode deixar de agir, o que levou Arendt a dignificar a ação como a atividade humana por excelência. Porém, a questão que preocupou Marx estava diretamente relacionada a este fato: de que podemos colocar outros para trabalhar para nós e que podemos não acrescentar nenhum objeto ao mundo, entretanto, a liberdade, para Marx, deveria abarcar a totalidade dos homens, esta mesma liberdade que é para ele a essência do homem.

Contudo, o objetivo de Arendt não é colocar as teses marxistas em dúvida para em seu lugar elaborar uma nova interpretação da sociedade capitalista; seu objetivo é tirar o trabalho em sua dupla forma do lugar central que Marx o colocou e substituí-lo pela ação e pela política como atividade mais nobre da vita activa. Porém, da perspectiva de Marx, os conceitos de Arendt como trabalho, enquanto atividade pouco nobre e ligada à manutenção da sobrevivência cotidiana e a animalidade da espécie humana, e "ação", enquanto atos que revelam quem o homem é em sua singularidade, mas sem conteúdo material, seriam simples aspectos de alienações e idealismos, fadados a desaparecer. A consciência, como resultado da realidade material, e a determinação econômica na constituição da consciência não assumem papel relevante nas interpretações de Arendt. Ao contrário de Marx, ela separa a relação marxiana entre pensamento e ação:

... os princípios pelos quais agimos e os critérios pelos quais julgamos e conduzimos nossas vidas dependem em última instância da vida do espírito (mind). Em suma dependem do desempenho aparentemente não lucrativo dessas empresas espirituais que não produzem resultados e 'não nos dotam diretamente com o poder de agir'(Heidegger). ${ }^{39}$

Para Marx, não devemos procurar categorias gerais ou princípios que expliquem cada período histórico e as ações humanas, mas "permanecer sempre sobre o solo da história real; não de explicar a práxis a partir da ideia, mas de explicar as formações ideológicas a partir da práxis material", 40 há uma conexão entre o pensamento e a ação, e a primazia cabe à ação. Na segunda tese sobre Feuerbach, Marx investe contra a ideia de um mundo do pensamento isolado, independente e não condicionado pela práxis:

A questão de saber se cabe ao pensamento humano uma verdade objetiva não é uma questão teórica, mas prática. É na práxis que o homem deve demonstrar a verdade, isto é, a realidade e o poder, o caráter terreno de seu pensamento. A disputa sobre a realidade ou não-realidade do pensamento isolado da práxis - é uma questão escolástica. ${ }^{41}$

Arendt, por sua vez, mantém independentes pensamento e ação, vita contemplativa e vita activa; fica a meio caminho entre as posições de Marx, de que a realidade determina o pensamento, e aqueles a quem Marx critica no início de $A$ ideologia alemãa, que, com o pensamento, acreditam poder modificar o mundo. Para Arendt, o conteúdo material (objetos) do que pensamos, queremos e

39 ARENDT, Hannah. A vida do espirito. Op. cit. p. 56.

${ }^{40}$ MARX, K., ENGELS. A ideologia alemã. Op. cit. p. 56.

${ }^{41}$ MARX, K., ENGELS. Teses sobre Feuerbach. In: A ideologia alemã. Op. cit. p. 12. 
julgamos nos é dado pelo mundo ao qual estamos condicionados e nos quais se desenvolve a vita activa que é explorada em suas diferenças em $A$ condição bumana; entretanto, as bases ou fundamentos (princípios) pelos quais nos guiamos no mundo são dados pela vida do espírito, as atividades da mente, que são incondicionadas e independem do mundo:

É certo que os objetos do meu pensar, querer, julgar, aquilo de que o espírito se ocupa, são dados pelo mundo ou surgem da minha vida neste mundo; mas eles como atividades não são nem condicionados nem necessitados quer pelo mundo, quer pela minha vida no mundo. Os homens, embora totalmente condicionados existencialmente - limitados pelo período de tempo entre o nascimento e a morte, submetidos ao trabalho para viver, levados a trabalhar para se sentir em casa no mundo e incitados a agir para encontrar o seu lugar na sociedade de seus semelhantes - , podem espiritualmente transcender todas essas condições, mas só espiritualmente; jamais na realidade ou na cognição e no conhecimento em virtude dos quais estão aptos para explorar a realidade do mundo e a sua própria realidade. Os homens podem julgar afirmativa ou negativamente as realidades em que nascem e pelas quais são também condicionados; podem querer o impossível, como, por exemplo, a vida eterna; e podem pensar, isto é, especular de maneira significativa sobre o desconhecido e o incognoscível. E embora isso jamais possa alterar diretamente a realidade - como de fato não há, em nosso mundo, oposição mais clara e radical do que a oposição entre pensar e fazer... ${ }^{42}$

A vida mental, no que concorda com Marx, não é suficiente para mudar a realidade e as condições em que o homem é e está submetido, tanto as que lhe foram dadas quanto as por ele mesmo feitas, mas os princípios que regem a ação e o instaurar no mundo de novas possibilidades são dados pelo pensamento, o que para Marx é simplesmente ideologia, é não perceber que são as condições às quais os homens estão submetidos que lhes voltam, de certa maneira, na forma de princípios teóricos.

As atividades da vida do espírito/mente, sendo independentes e não condicionadas pela vita activa, criam aparentemente dois mundos distintos, um interno e outro externo; mas esta aparente divisão pode ser desfeita a partir da linguagem e da ideia de metáfora como metapherein, transferência; "Não há dois mundos, pois a metáfora os une". ${ }^{43}$ Arendt deixa-nos como hipótese de que a vida interna e suas atividades se relacionam com a atividade "externa" através da linguagem; a linguagem seria "o único meio no qual o invisível (o mundo interno) pode tornar-se manifesto em um mundo de aparências" "44, a linguagem e a metáfora seriam os responsáveis por estabelecer o nexo entre pensar e fazer, vita contemplativa e vita activa.

\footnotetext{
${ }^{42}$ ARENDT, Hannah. A vida do espírito. Op. cit. p. 56.

43 Ibid. p. 84.

44 Ibid. p. 86.
} 


\section{REFERÊNCIAS:}

ALTHUSSER, Louis. A favor de Marx. Trad. Dirceu Lindoso. Rio de Janeiro: Zahar Editores, 1979.

ARENDT, Hannah. A condição bumana. Tradução Roberto Raposo, revisão técnica: Adriano Correia - $11^{a}$ ed. Rio de Janeiro. Forense Universitária, 2010.

ARENDT, Hannah. A vida do espirito. O pensar, o querer, o julgar. Trad. Antônio Abranches, César A. R. de Almeida, Helena Martins. Rio de Janeiro: Relume-Dumará, 1993.

ARENDT, Hannah. Entre o passado e o futuro. São Paulo: Editora Perspectiva, 1992.

ARENDT, Hannah. Origens do totalitarismo. Trad. Roberto Raposo. 3v: Anti-semitismo, imperialismo, totalitarismo. São Paulo: Companhia das Letras, 1989.

ARENDT, Hannah. The Human Condition. Chicago. University of Chicago Press, 1998.

BOTTOMORE, Tom. Org. Karl Marx. Trad. Nathanael C. Caixeiro. Rio de Janeiro: Zahar Editores, 1981.

ESCOBAR, C.H. Ciência da história e ideologia. Rio de Janeiro: Edições Graal, 1979

HELLER, Agnes. Sociología de la vida cotidiana. Prefacio de György Lukacs. Trad. J.F. Yvars, E. Pérez Nadal. Barcelona: Ediciones Península, 1994.

LEFEBVRE, Henri. O marxismo. Trad. J. Guinsburg. São Paulo: Difusão Européia do Livro, 1974.

MARX, K. O Capital. Trad. Regis Barbosa, Flávio R. Kothe. Apresentação de Jacob Gorender. São Paulo: Nova Cultural, 1996.

MARX, K., ENGELS, LENINE. Sobre o humanismo na sociedade comunista. Obras Escolhidas. Trad. Franco de Souza. Lisboa: Seara Nova, 1977.

MARX, K., ENGELS. A ideologia alemã. Trad. José Carlos Bruni, Marco A. Nogueira. São Paulo: Hucitec, 1993.

MARX, K., ENGELS. Obras Escolbidas. São Paulo: Editora Alfa-Omega. s/d. 3v. 